\title{
Perioperation ulinastatin intervention protects liver function in hepatectomy: a systematic review of randomized controlled trials and meta-analysis
}

\author{
Hong Gao ${ }^{1 \#}$, Yi Lyu ${ }^{2 \#}$, Yi Yang ${ }^{3 \#}$, Yingchuan $\mathrm{Li}^{4}$, Honghua Cao ${ }^{5}$ \\ ${ }^{1}$ Department of Emergency, The First People's Hospital of Qujing, Qujing 655000, China; ${ }^{2}$ Department of Anesthesiology, Minhang Hospital, \\ Fudan University, Shanghai 201100, China; ${ }^{3}$ Department of Oncological Surgery, Kunshan Traditional Chinese Medicine Hospital Affiliated to \\ Nanjing University of Chinese Medicine, Suzhou 215300, China; ${ }^{4}$ Department of Intensive Care Unit, Shanghai Jiao Tong University Affiliated \\ Sixth People's Hospital, Shanghai 200233, China; ${ }^{5}$ Department of Hematology, Tumor Hospital of Yunnan Province \& The Third Affiliated Hospital \\ of Kunming Medical University, Kunming 650118, China \\ Contributions: (I) Conception and design: H Gao, Y Lyu, H Cao; (II) Administrative support: H Gao, Y Lyu, Y Yang; (III) Provision of study materials \\ or patients: Y Yang, Y Li; (IV) Collection and assembly of data: H Gao, Y Lyu, Y Yang; (V) Data analysis and interpretation: Y Yang, Y Li; (VI) \\ Manuscript writing: All authors; (VII) Final approval of manuscript: All authors. \\ \#These authors contributed equally to this work. \\ Correspondence to: Honghua Cao, MD. Department of Hematology, Tumor Hospital of Yunnan Province \& The Third Affiliated Hospital of \\ Kunming Medical University, Kunming 650118, China. Email: Caohh787878@163.com.
}

\begin{abstract}
Background: Vascular occlusion during hepatectomy accompanies ischemia-reperfusion (IR) injury, which can cause liver dysfunction and affect patients' outcome. Ulinastatin or urinary trypsin inhibitor (UTI), a polyvalent inhibitor of various enzymes, has been confirmed of anti-IR injury effect in recent studies. Here we performed a systematic review and meta-analysis to assess the benefits of perioperation UTI using to protect liver function in hepatectomy.
\end{abstract}

Methods: Randomized controlled trials (RCTs) evaluating UTI in hepatectomy were identified. Two independent reviewers extracted data on basic characteristics and risk of bias in the studies, and on outcomes such as alanine transaminase (ALT), aspartate transaminase (AST), and total bilirubin (TBIL) from 1 to 7 days after operation.

Results: A total of 9 RCTs including 408 UTI and 372 control participants were identified. There was no significant difference in basic characteristics such as age or sex. The majority of the patients who underwent hepatectomy had primary liver carcinoma, liver metastases and benign liver lesions. A significant improvement in liver function was associated with UTI use not only at 1 and 3 days postoperatively, but also at 7 days (all $\mathrm{P} \leq 0.01$ ). However, significant heterogeneity existed between the pooled studies (all $\mathrm{P}<0.01$ ).

Conclusions: UTI has positive protective effects against IR injury in hepatectomy. However, further highquality RCTs are needed to confirm this conclusion.

Keywords: Hepatectomy; urinary trypsin inhibitor (UTI); vascular occlusion; liver function; ischemia-reperfusion (IR)

Submitted Sep 06, 2019. Accepted for publication Feb 11, 2020.

doi: 10.21037/apm.2020.04.28

View this article at: http://dx.doi.org/10.21037/apm.2020.04.28

\section{Introduction}

Since the first successful planned liver resection done by Langenbuch in 1888 , hepatectomy has been improved for over 130 years: Wendel did the first hemihepatectomy;
Lortat-Jacob and Robert performed the first inflow ligation resection (1) and till today we have much more operation types to choose such as local resection, hepatic segmentectomy and multiple segmentectomy. Hepatectomy 
remains the only potential curative treatment for liver lesions primary or metastatic liver disease, benign liver lesions and other liver diseases. In order to reduce blood loss during liver operation, various methods of vascular occlusion have been used (2). Although it seemed that the incidence of liver failure did not increase, many studies revealed that the liver enzymes were significantly elevated after vascular occlusion (3), and the potential mechanism might be ischemia-reperfusion (IR) injury.

IR injury of the liver is a complex multi-path process leading to the activation of inflammatory pathways. Cellular injury occurs during both the ischemic and reperfusion phases (4), especially in reperfusion phase. Reperfusion injury, which follows the ischemic injury, results not only from metabolic disturbances but also from a profound inflammatory immune response that involves both direct and indirect cytotoxic mechanisms (5). Indeed, inflammatory plays a so critical role in IR injury that various pharmacological agents have been attempted to decrease inflammation during hepatectomy.

Ulinastatin or urinary trypsin inhibitor (UTI) is a Kunitz-type serine protease inhibitor that plays an antiinflammatory effect by inhibiting several proteases such as trypsin, plasmin, cathepsin G, chymotrypsin, and neutrophil elastase (6). Animal studies (7-10) and human studies $(11,12)$ showed that UTI administration suppressed acute inflammatory responses after hepatectomy. Since there was no systematic review or meta-analysis of randomized controlled trials (RCTs) to assess the benefits of UTI in hepatectomy, whether perioperatively UTI using has a protective effect on liver function remained unclear. Here we performed a systematic review and meta-analysis to evaluate the efficiency of UTI in liver protection in patients with hepatectomy.

\section{Methods}

This meta-analysis was performed according to the guidelines for 'preferred reporting items for systematic reviews and meta-analyses' (the 'PRISMA' statement) (13), and the methodology set forth in the Cochrane Handbook for Systematic Reviews of Interventions (14).

\section{Data retrieval strategies}

Electronic databases, including PubMed, Cochrane, Embase, CNKI and CBMdisc were searched by two independent researchers between Jan 2001 to May 2019.
The following keywords were used: liver function, liver enzyme, hepatectomy, liver resection, ulinastatin, IR injury and UTI. Two independent reviewers searched the databases using these keywords to identify potentially relevant articles. Reference lists of the relevant articles were also reviewed for any additional relevant studies. The search was not restricted by language.

\section{Inclusion criteria}

Studies were identified according to the following inclusion criteria: (I) participants: human with relevant diseases requiring hepatectomy, (II) comparison: patients with UTI treatment versus those without UTI, (III) outcome: trials that reported liver function, and (IV) methodological criterion: a prospective RCT.

\section{Data extraction}

Two authors extracted relevant data independently, including the first author's name, publication year, the size of the UTI and control groups, average age of participants, gender ratio, duration of surgery, surgery types and UTI protocol, alanine transaminase (ALT), aspartate transaminase (AST), and total bilirubin (TBIL) before and after treatment. Intention-to-treat (ITT) data gathered from the studies were used as long as it was available. Otherwise, available data were used.

\section{Quality assessment}

According to the risk-of-bias assessment tool outlined in the Cochrane Handbook for Systematic Reviews of Interventions (version 5.1.0) (15), the methodological quality of each included RCT was assessed by two independent researchers. Briefly, six domains are evaluated: random sequence generation, allocation concealment, blinding of patients and personnel, blinding of outcome assessment, incomplete outcome data, and selective reporting risk. Risks of bias figures were generated using Cochrane Review Manager Software 5.3.

\section{Outcome measures and data analysis}

The outcome measures were changed in ALT, AST and TBIL after treatment. For all included studies, posttreatment measurements were summarized as mean \pm standard deviation (SD). 


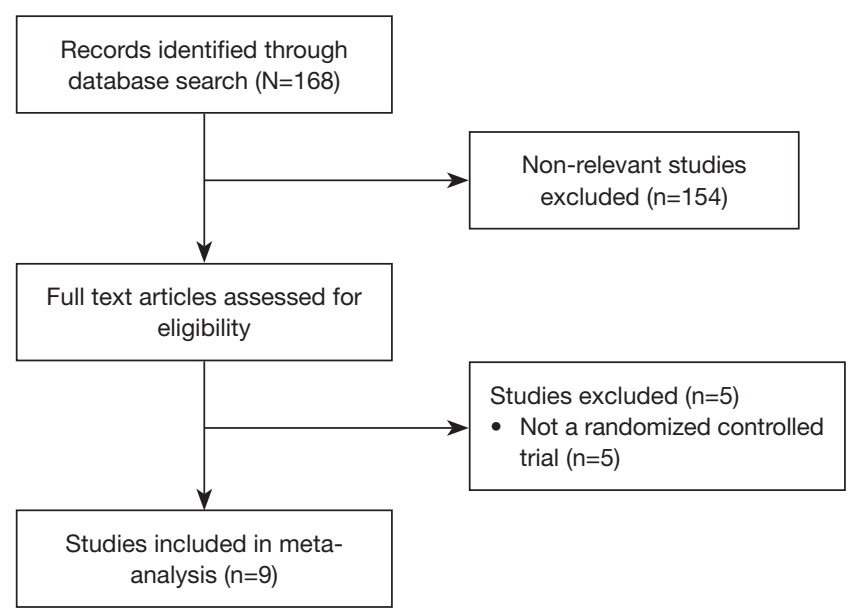

Figure 1 Flow chart of identified, included and excluded studies.

Statistical analyses were performed using Review Manager 5.0 (RevMan 5) computer program (developed by the Cochrane Collaboration). Heterogeneity was assessed by calculating the Cochran $\mathrm{Q}$ and the $\mathrm{I}^{2}$ statistic. A Cochran $\mathrm{Q}$ with $\mathrm{P}<0.121$ or an $\mathrm{I}^{2}$ statistic $>50 \%$ (16) indicated heterogeneity between studies. Depending on the level of heterogeneity, study-specific RRs were pooled using a fixed-effect model or a random-effects model. If high heterogeneity existed, a random-effect model was used (17); otherwise, a fixed-effect model was used. Sensitivity analysis was conducted based on the leave-one-out approach for ALT, AST and TBIL. Assessment of publication bias was estimated using funnel plots. For all statistical analyses, with the exception of heterogeneity, a value of $\mathrm{P}<0.05$ was considered to indicate statistical significance, and all tests were two-sided.

\section{Results}

\section{Study selection}

Figure 1 is a flow diagram of study selection. Through the database search, a total of 168 studies (137 in Chinese and 31 in English) were identified, and 154 non-relevant studies were excluded. Subsequently, the full texts of the 14 articles were reviewed and 5 non-RCT studies were excluded. Thus, 9 studies were included in the meta-analysis.

\section{Study characteristics}

The basic characteristics of the studies are presented in Table 1. The total number of participants in the treatment groups was 408 (range, 14-80), and in the control groups was 372 (range, 14-78). In those studies, most participants were males $(69.7 \% \pm 10.1 \%)$ and the mean age was about $47.9 \pm 8.1$ years old. The mean follow-up time ranged from 1 to 7 days. In the included studies, $80 \%$ to $100 \%$ of the patients had primary carcinoma of the liver, liver metastases and benign liver lesions, and the rest of patients with hepatectomy were diagnosed as hepatolithiasis. The demographic baselines of the two groups in each included RCT were comparable.

\section{Study quality}

Figure 2 shows the quality of the included studies. Among the included studies, only Fan 2015 was at low risk of bias.

\section{UTI usage}

All the studies started UTI treatment before or during operation. Three studies $(20,23,26)$ used UTI 200,000 U (I.V.) twice a day for 5-7 consecutive days; one study (25) conducted UTI 200,000 U (I.V.) once a day and lasted to 9 days after operation; Fan's study (19) included a UTI treatment of 10,000 U (I.V.) before and $2 \mathrm{~h}$ after operation and 3 times for 7 consecutive days; other studies performed UTI 150,000 U (I.V.) once or twice a day for 3 consecutive days $(21,22)$. In Zhang's study (18), the protocol of UTI treatment was $200,000 \mathrm{U} / \mathrm{kg}$ before and $2 \mathrm{~h}$ after operation and remained twice a day for 5 consecutive days, which was a much larger dosage than other studies. Moreover, $\mathrm{Li}$ and his colleagues chose UTI 10,000 U/kg only during operation (24), which was smaller than other studies. Besides Zhang's and Li's studies, the total dosage of UTI per patient ranged from $1,050,000$ to $3,200,000 \mathrm{U}$.

\section{Outcomes of liver function}

\section{Change of AST}

Eight studies reported 1-day, seven studies reported 3-day, and five studies reported 5- and 7-day postoperative AST test result (Table 2). Heterogeneity tests showed all $\mathrm{I}^{2}>95 \%$ and all $\mathrm{P}<0.01$, indicating that heterogeneity but not clinical heterogeneity existed in studies. So random effects models were chosen. According to meta-analysis results, post operation AST was significantly lower in the UTI group compared with Control group [1-day: weighted mean difference (WMD): $-34.46,95 \%$ CI: -58.59 to -10.34 , $\mathrm{P}=0.005$; 3-day: WMD: $-30.41,95 \% \mathrm{CI}:-44.30$ to -16.52 , 


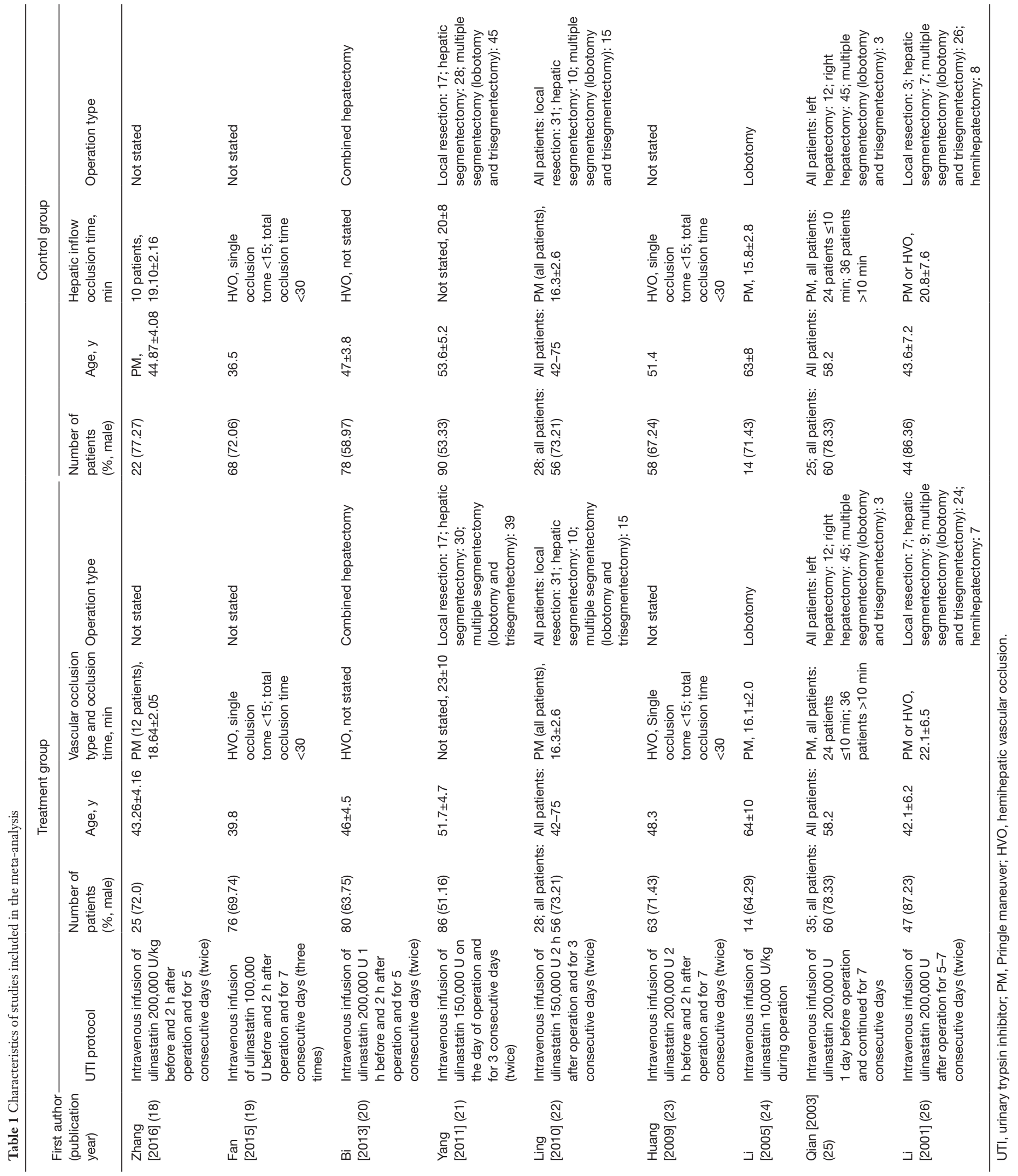




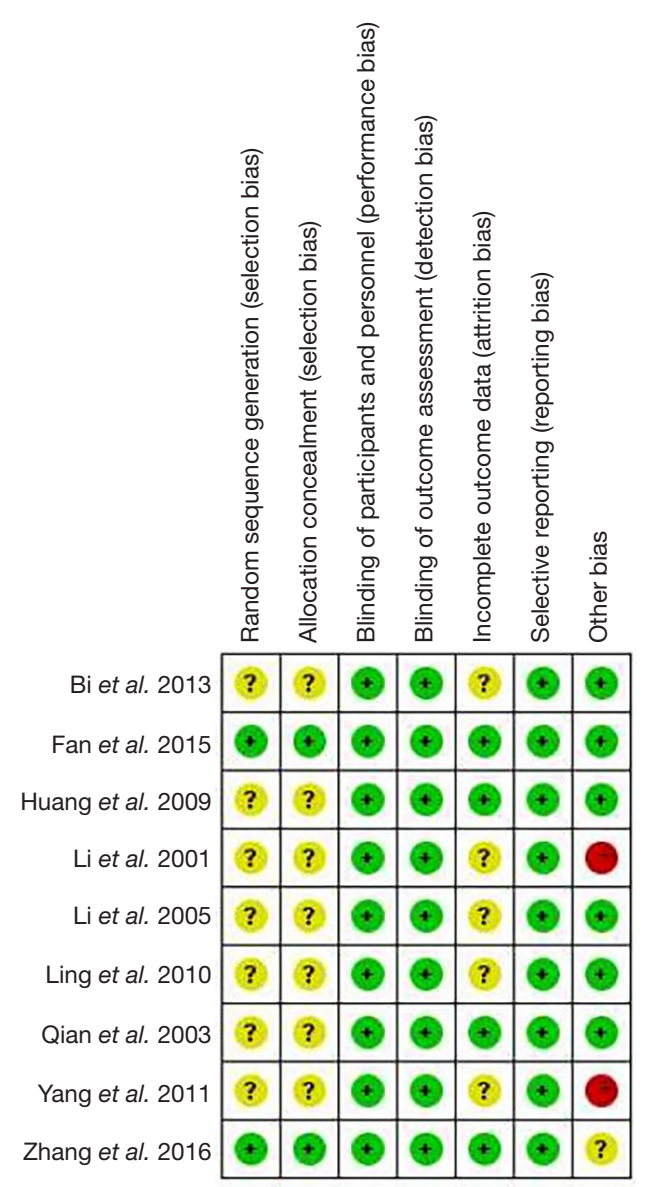

Figure 2 Individual methodological quality criteria for each study included.

$\mathrm{P}<0.0001 ;$-day: WMD: $-22.07,95 \% \mathrm{CI}:-35.04$ to -9.11 , $\mathrm{P}=0.0008$; 7-day: WMD: $-18.44,95 \% \mathrm{CI}:-26.31$ to -10.57 , $\mathrm{P}<0.0001$; Figures 3-6].

\section{Change of ALT}

All of the nine studies reported 1-day postoperative ALT. Eight studies reported 3-day and six studies reported 5and 7-day postoperative ALT (Table 3). Heterogeneity tests showed all $\mathrm{I}^{2}>90 \%$ and all $\mathrm{P} \leq 0.01$, indicating that heterogeneity but not clinical heterogeneity existed in studies. Thus we used random effects models and found that postoperative ALT was significantly lower in the UTI group compared with Control group (1-day: WMD: $-42.93,95 \%$ CI: -61.56 to $-24.29, \mathrm{P}<0.0001$; 3-day: WMD: $-34.45,95 \%$ CI: -45.31 to $-23.59, \mathrm{P}<0.0001$; 5-day: WMD: $-20.47,95 \%$ CI: -36.81 to $-4.13, \mathrm{P}=0.01$; 7-day: WMD: $-21.59,95 \%$ CI: -31.53 to $-11.65, \mathrm{P}<0.0001$; Figures $7-10$ ).

\section{Change of TBIL}

All of the nine studies reported 1-day postoperative TBIL. Eight studies reported 3-day and six studies reported 5- and 7-day postoperative TBIL (Table 4). Heterogeneity tests showed all $\mathrm{I}^{2}>90 \%$ and all $\mathrm{P}<0.01$, indicating the existence of heterogeneity in studies. Again, we performed random effects models. Compared with Control group, postoperative TBIL decreased significantly in the UTI group according to the results of meta-analysis (1-day: WMD: $-4.50,95 \% \mathrm{CI}:-7.39$ to $-1.61, \mathrm{P}=0.002$; 3-day: WMD: $-8.98,95 \% \mathrm{CI}:-13.46$ to $-4.51, \mathrm{P}<0.0001$; 5-day: WMD: -7.49 , 95\% CI: -11.53 to $-3.45, \mathrm{P}=0.0003$; 7-day: WMD: $-3.90,95 \% \mathrm{CI}:-6.08$ to $-1.72, \mathrm{P}=0.0005$; Figures 11-14).

\section{Discussion}

\section{Effectiveness}

UTI, an acidic glycoprotein with a molecular weight of 67,000 , is a protease inhibitor purified from fresh human urine $(27,28)$. In clinical treatment, UTI has been widely used in acute pancreatitis and shock $(29,30)$. As a protease inhibitor, UTI holds the ability to reduce the activation of leukocytes and the release of inflammatory cytokines in liver IR injury (31). Moreover, UTI stabilizes lysosomal membranes and suppresses the release of lysosomal enzymes (32). In our study, hepatic IR caused notable hepatocellular damage since liver enzymes such as AST, ALT and TBIL elevated significantly, and the degree of liver injury was remarkably reduced by UTI. Some studies revealed that postoperative liver function and enzyme markers of liver injury increased much more in Pringle maneuver (PM) than that in hemihepatic vascular occlusion (HVO) compared with preoperative results $(33,34)$. Furthermore, liver metabolism and tissue oxygenation were markedly affected by occlusion of the liver hilus (35). In other words, both vascular occlusion type and liver ischemia time would affect patients' preoperative liver function. Five of the nine studies in our metaanalysis took PM to occlude liver blood flow, and most studies had a vascular occlusion time over 15 minutes, indicating severer hepatic injury. Based on these results, it seems that UTI may offer a protective role in hepatectomy under vascular occlusion, especially in PM with long occlusion time.

\section{Subgroup analysis}

Patients with liver cirrhosis, steatosis or undergoing major liver resections with $\mathrm{PM}$ are known to be at high risk for developing IR injury $(36,37)$. For this reason, we intended 
Table 2 Outcomes of post operation AST (U/L)

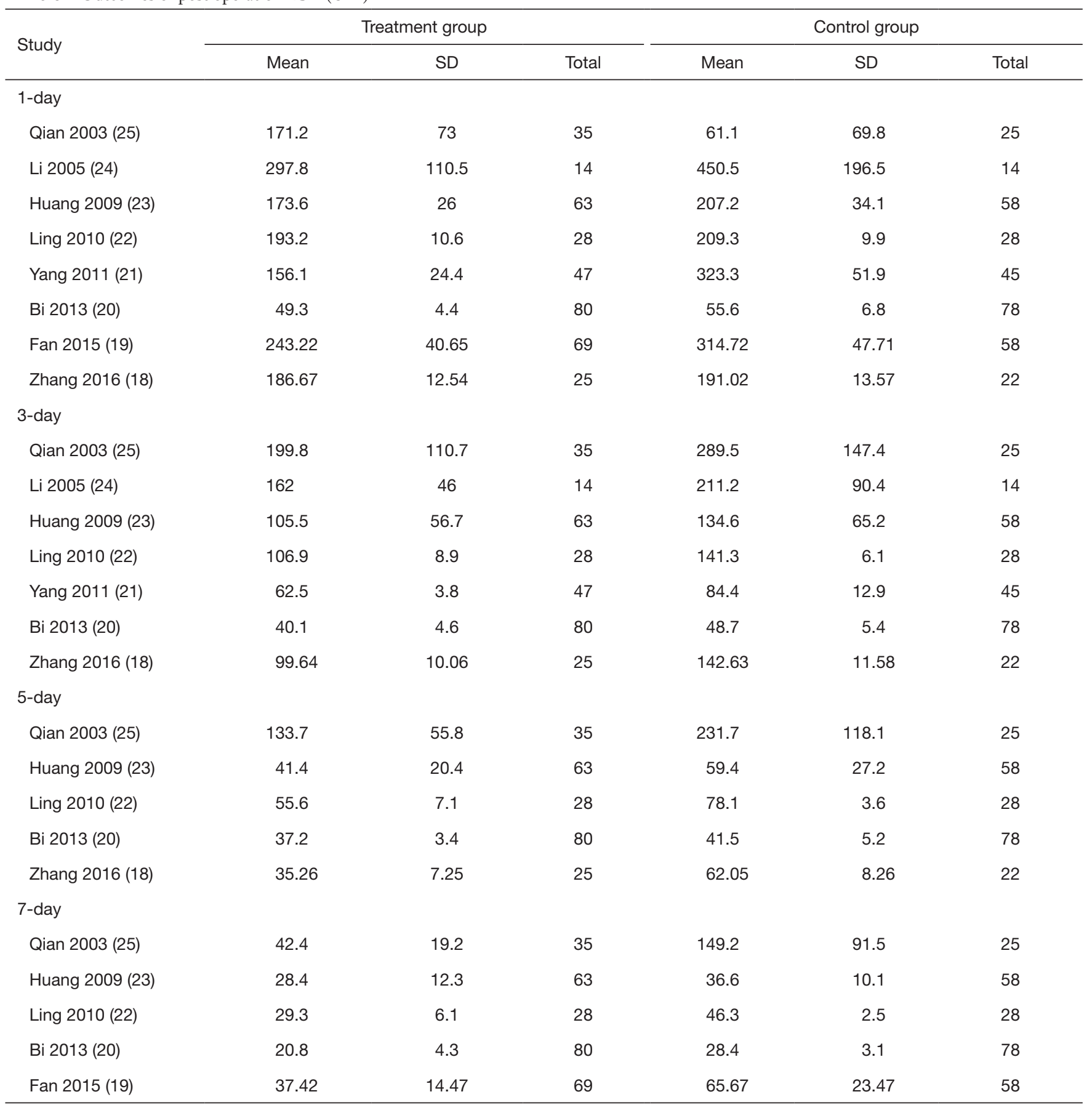

AST, aspartate transaminase; SD, standard deviation.

to perform a subgroup analysis on each of these. However, the lack of numerical reporting of patients in each of these subgroups and the few studies included within each comparison made us unable to do so.

\section{Quality of evidence and future trials}

In our meta-analysis, all the included studies were RCTs, which could reduce biases to some extent. However, only 


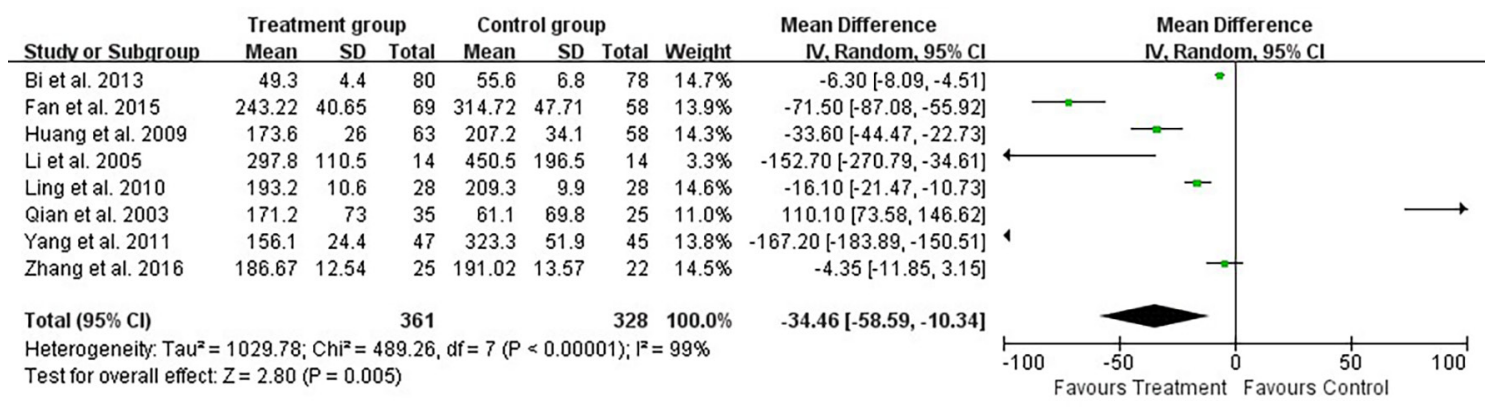

Figure 3 Forest plot of 1-day post operation AST. AST, aspartate transaminase.

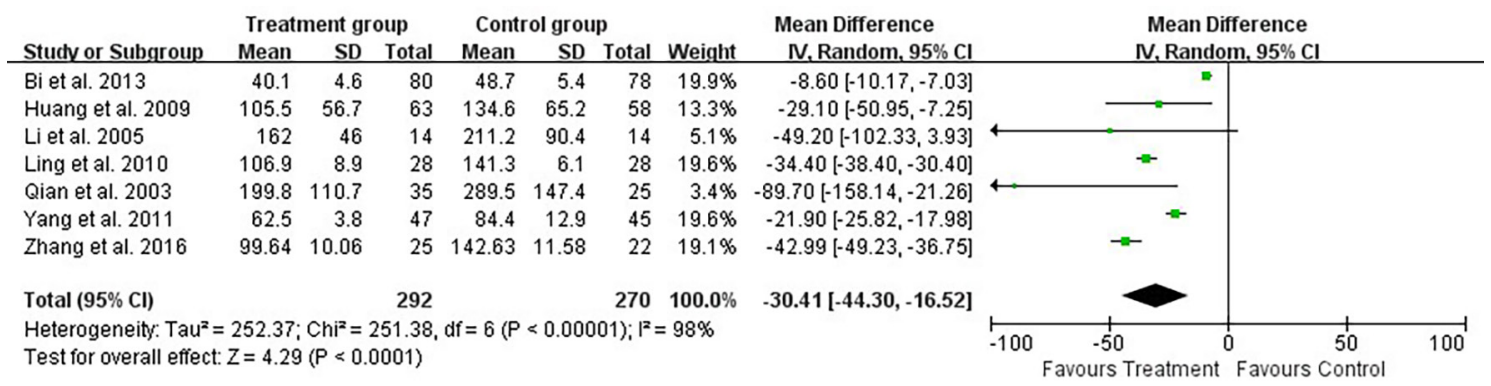

Figure 4 Forest plot of 3-day post operation AST. AST, aspartate transaminase.

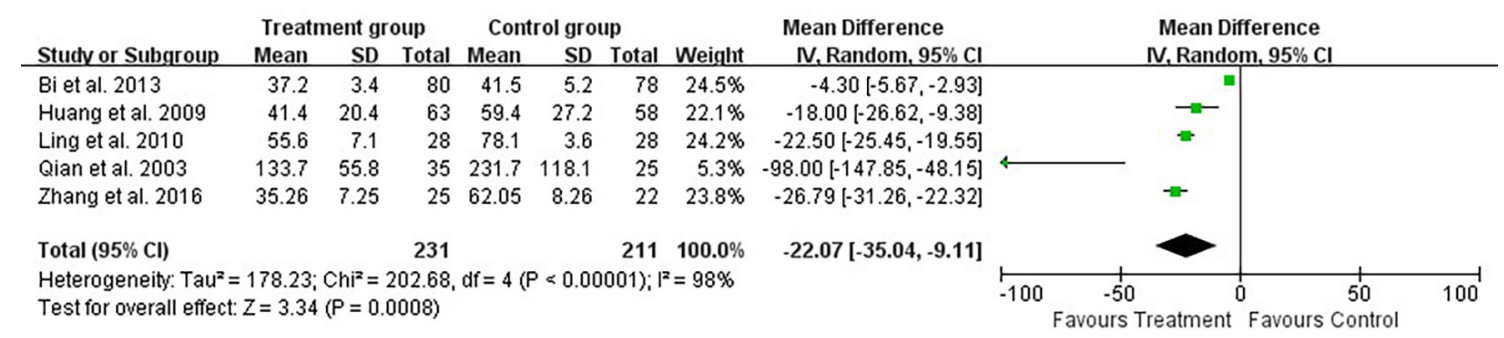

Figure 5 Forest plot of 5-day post operation AST. AST, aspartate transaminase.

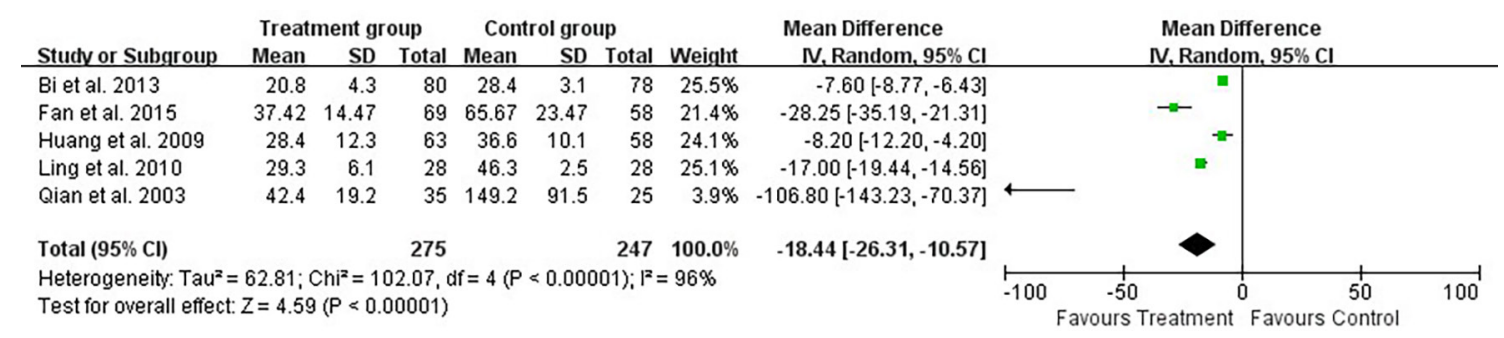

Figure 6 Forest plot of 7-day post operation AST. AST, aspartate transaminase. 
Table 3 Outcomes of post operation ALT (U/L)

\begin{tabular}{|c|c|c|c|c|c|c|}
\hline Study & \multicolumn{3}{|c|}{ Treatment group } & \multicolumn{3}{|c|}{ Control group } \\
\hline \multicolumn{7}{|l|}{ 1-day } \\
\hline Li 2001 (26) & 496.5 & 62.1 & 47 & 562.1 & 52.2 & 44 \\
\hline Qian 2003 (25) & 106 & 74 & 35 & 177.6 & 85.1 & 25 \\
\hline Huang 2009 (23) & 249.3 & 56.3 & 63 & 304.8 & 136.2 & 58 \\
\hline Ling 2010 (22) & 249.5 & 16.8 & 28 & 252.3 & 14.9 & 28 \\
\hline Yang 2011 (21) & 246.1 & 38.8 & 47 & 355.5 & 56.9 & 45 \\
\hline Bi 2013 (20) & 65.6 & 6.1 & 80 & 72.7 & 10.6 & 78 \\
\hline \multicolumn{7}{|l|}{ 3-day } \\
\hline Li 2001 (26) & 391.8 & 52.1 & 47 & 452.6 & 41.2 & 44 \\
\hline Qian 2003 (25) & 128.3 & 84.3 & 35 & 206.9 & 126.5 & 25 \\
\hline Li 2005 (24) & 127.8 & 37.6 & 14 & 187.5 & 150.4 & 14 \\
\hline Huang 2009 (23) & 98.7 & 62.7 & 63 & 126.8 & 45.2 & 58 \\
\hline Ling 2010 (22) & 106.8 & 9.7 & 28 & 136.5 & 11.2 & 28 \\
\hline Yang 2011 (21) & 141.1 & 22 & 47 & 181.9 & 28.7 & 45 \\
\hline Bi 2013 (20) & 49.8 & 7.2 & 80 & 64.8 & 6.2 & 78 \\
\hline Ling 2010 (22) & 55.1 & 4.6 & 28 & 98.6 & 10.3 & 28 \\
\hline Bi 2013 (20) & 41.4 & 4.8 & 80 & 48.7 & 5.5 & 78 \\
\hline Zhang 2016 (18) & 49.02 & 8.64 & 25 & 78.69 & 7.24 & 22 \\
\hline \multicolumn{7}{|l|}{ 7-day } \\
\hline Li 2001 (26) & 58.7 & 16.2 & 47 & 69.5 & 15.4 & 44 \\
\hline Qian 2003 (25) & 31.6 & 8.2 & 35 & 76.6 & 36.2 & 25 \\
\hline Huang 2009 (23) & 25.6 & 10.8 & 63 & 37.9 & 9.5 & 58 \\
\hline Ling 2010 (22) & 28.3 & 6.5 & 28 & 60.3 & 5.1 & 28 \\
\hline Bi 2013 (20) & 23.6 & 5.1 & 80 & 32.5 & 4.3 & 78 \\
\hline Fan 2015 (19) & 31.32 & 11.73 & 69 & 57.56 & 12.08 & 58 \\
\hline
\end{tabular}

ALT, alanine transaminase; SD, standard deviation. 


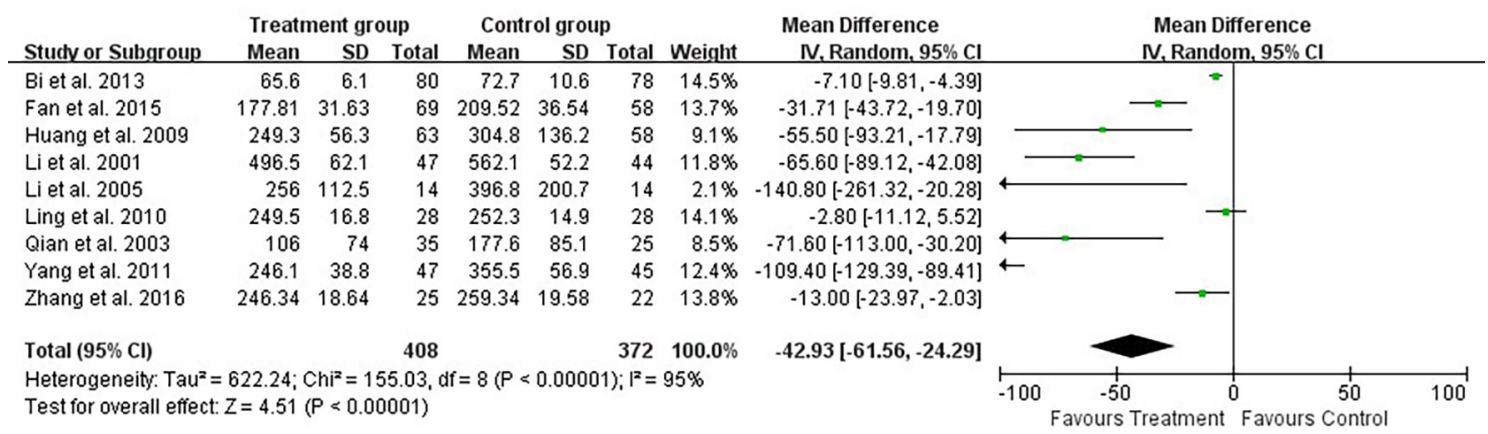

Figure 7 Forest plot of 1-day post operation ALT. ALT, alanine transaminase.

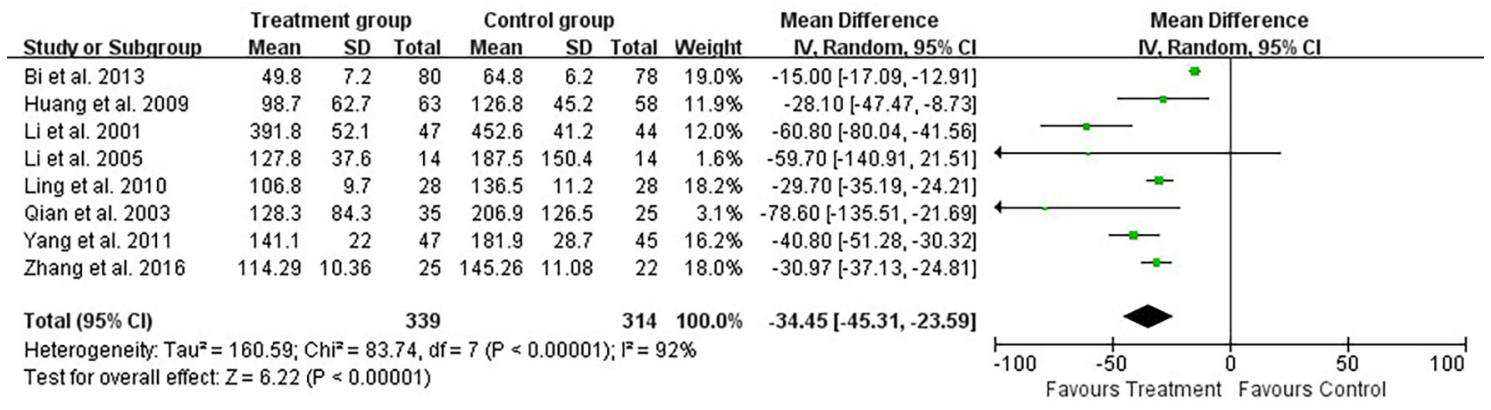

Figure 8 Forest plot of 3-day post operation ALT. ALT, alanine transaminase.

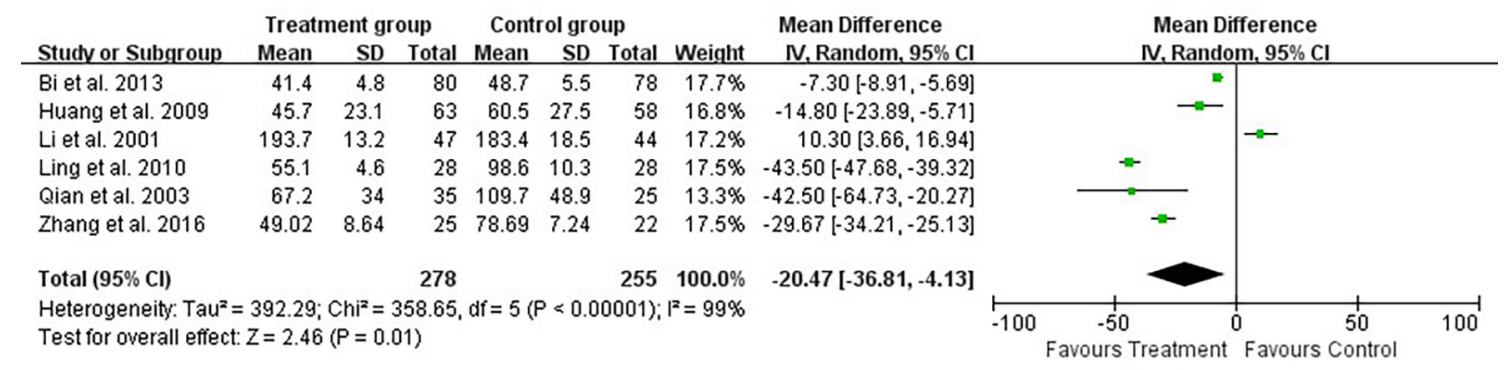

Figure 9 Forest plot of 5-day post operation ALT. ALT, alanine transaminase.

\begin{tabular}{|c|c|c|c|c|c|c|c|c|c|c|c|c|}
\hline \multirow[b]{2}{*}{ Studv or Subgroup } & \multicolumn{3}{|c|}{ Treatment group } & \multicolumn{3}{|c|}{ Control group } & \multirow[b]{2}{*}{ Weight } & \multirow{2}{*}{$\begin{array}{l}\text { Mean Difference } \\
\text { IV. Random, } 95 \% \mathrm{CI}\end{array}$} & \multirow{2}{*}{\multicolumn{4}{|c|}{$\begin{array}{c}\text { Mean Difference } \\
\text { IV. Random, } 95 \% \mathrm{Cl}\end{array}$}} \\
\hline & Mean & SD & Total & Mean & SD & Total & & & & & & \\
\hline Bi et al. 2013 & 23.6 & 5.1 & 80 & 32.5 & 4.3 & 78 & $17.9 \%$ & $-8.90[-10.37,-7.43]$ & & $=$ & & \\
\hline Fan et al. 2015 & 31.32 & 11.73 & 69 & 57.56 & 12.08 & 58 & $17.4 \%$ & $-26.24[-30.40,-22.08]$ & & - & & \\
\hline Huang et al. 2009 & 25.6 & 10.8 & 63 & 37.9 & 9.5 & 58 & $17.5 \%$ & $-12.30[-15.92,-8.68]$ & & + & & \\
\hline Li et al. 2001 & 58.7 & 16.2 & 47 & 69.5 & 15.4 & 44 & $16.6 \%$ & $-10.80[-17.29,-4.31]$ & & $\rightarrow-$ & & \\
\hline Ling et al. 2010 & 28.3 & 6.5 & 28 & 60.3 & 5.1 & 28 & $17.6 \%$ & $-32.00[-35.06,-28.94]$ & & $=$ & & \\
\hline Qian et al. 2003 & 31.6 & 8.2 & 35 & 76.6 & 36.2 & 25 & $13.0 \%$ & $-45.00[-59.45,-30.55]$ & & & & \\
\hline Total $(95 \% \mathrm{Cl})$ & & & 322 & & & 291 & $100.0 \%$ & $-21.59[-31.53,-11.65]$ & & & & \\
\hline $\begin{array}{l}\text { Heterogeneity: Tau } \\
\text { Test for overall effect }\end{array}$ & $\begin{array}{l}143.59 \\
Z=4.26\end{array}$ & $\begin{array}{l}\mathrm{Chi}^{2}=2 \\
(\mathrm{P}<0.0\end{array}$ & $\begin{array}{l}31.62, \\
001)\end{array}$ & $d f=5$ & 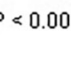 & 01); $1^{2}$ & $=98 \%$ & & $\stackrel{\longmapsto}{-10}$ & $\begin{array}{l}-50 \\
\text { avourTreatment }\end{array}$ & Favours C & $\begin{array}{l}50 \\
\text { Control }\end{array}$ \\
\hline
\end{tabular}

Figure 10 Forest plot of 7-day post operation ALT. ALT, alanine transaminase. 
Table 4 Outcomes of post operation TBIL $(\mu \mathrm{mol} / \mathrm{L})$

\begin{tabular}{|c|c|c|c|c|c|c|}
\hline Study & \multicolumn{3}{|c|}{ Treatment group } & \multicolumn{3}{|c|}{ Control group } \\
\hline \multicolumn{7}{|l|}{ 1-day } \\
\hline Li 2001 (26) & 11.9 & 2.5 & 47 & 12.8 & 2.9 & 44 \\
\hline Qian 2003 (25) & 38.1 & 25.2 & 35 & 64.9 & 40.9 & 25 \\
\hline Huang 2009 (23) & 33.5 & 5.2 & 63 & 39.3 & 9.3 & 58 \\
\hline Ling 2010 (22) & 33.6 & 2.8 & 28 & 35.1 & 1.6 & 28 \\
\hline Yang 2011 (21) & 16.76 & 3.8 & 47 & 15.39 & 3.9 & 45 \\
\hline Bi 2013 (20) & 30.2 & 4.6 & 80 & 38.2 & 3.6 & 78 \\
\hline \multicolumn{7}{|l|}{ 3-day } \\
\hline Li 2001 (26) & 16.8 & 1.7 & 47 & 17.1 & 2.1 & 44 \\
\hline Qian 2003 (25) & 55.8 & 36.9 & 35 & 89.8 & 64 & 25 \\
\hline Li 2005 (24) & 33 & 11.4 & 14 & 43.7 & 16.9 & 14 \\
\hline Huang 2009 (23) & 35 & 14.6 & 63 & 47.6 & 17.3 & 58 \\
\hline Ling 2010 (22) & 36.1 & 4.1 & 28 & 47.3 & 5.8 & 28 \\
\hline Yang 2011 (21) & 16.42 & 2.7 & 47 & 26.51 & 4.3 & 45 \\
\hline Bi 2013 (20) & 27.6 & 4.2 & 80 & 35.5 & 4.1 & 78 \\
\hline Ling 2010 (22) & 22.9 & 6.4 & 28 & 30.8 & 4.9 & 28 \\
\hline Bi 2013 (20) & 20.4 & 3.6 & 80 & 28.4 & 5.1 & 78 \\
\hline Zhang 2016 (18) & 20.06 & 8.42 & 25 & 32.02 & 5.13 & 22 \\
\hline \multicolumn{7}{|l|}{ 7-day } \\
\hline Li 2001 (26) & 11.8 & 1.9 & 47 & 12.2 & 2.2 & 44 \\
\hline Qian 2003 (25) & 14.7 & 8.4 & 35 & 29.4 & 16.1 & 25 \\
\hline Huang 2009 (23) & 17.9 & 2.8 & 63 & 22.3 & 6.9 & 58 \\
\hline Ling 2010 (22) & 18.5 & 1.9 & 28 & 24.1 & 3.2 & 28 \\
\hline Bi 2013 (20) & 13.1 & 3.2 & 80 & 14.2 & 3.1 & 78 \\
\hline Fan 2015 (19) & 14.75 & 3.56 & 69 & 19.16 & 3.06 & 58 \\
\hline
\end{tabular}

TBIL, total bilirubin; SD, standard deviation. 


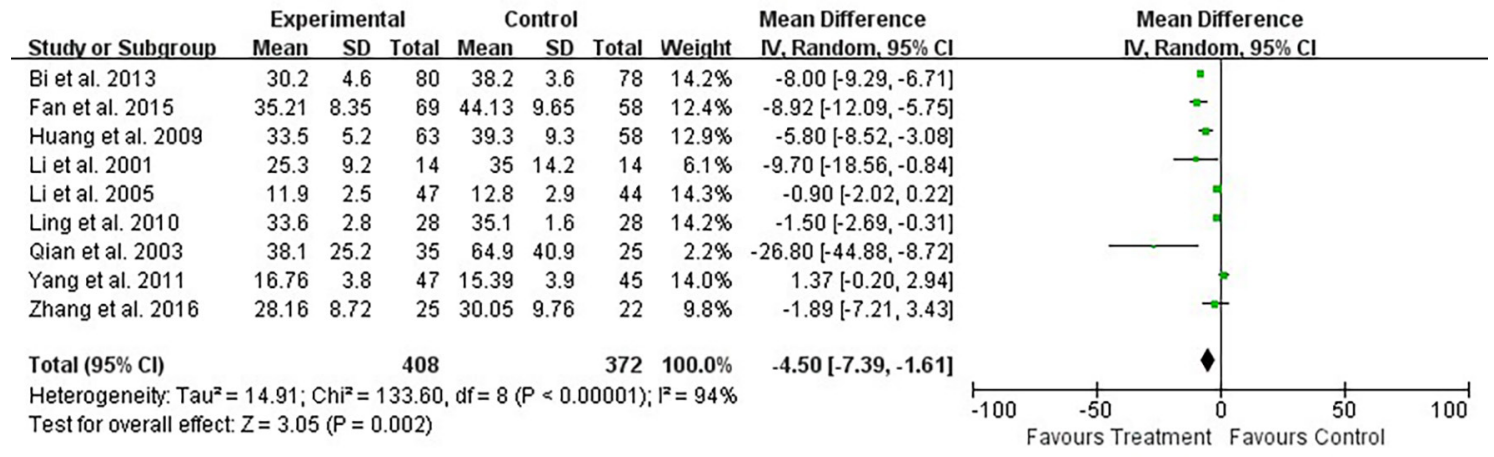

Figure 11 Forest plot of 1-day post operation TBIL. TBIL, total bilirubin.

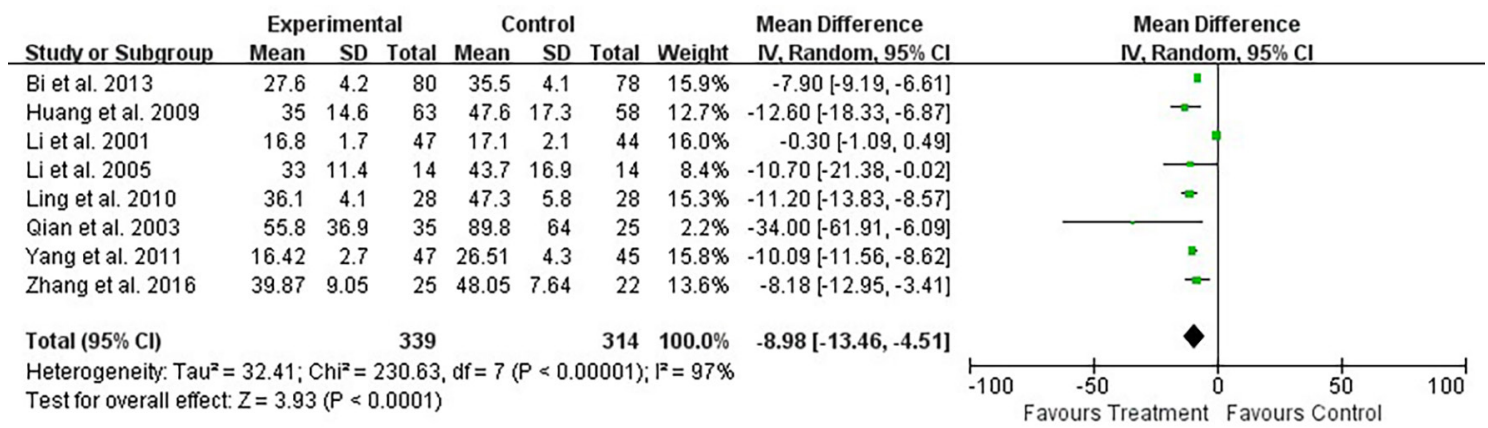

Figure 12 Forest plot of 3-day post operation TBIL. TBIL, total bilirubin.

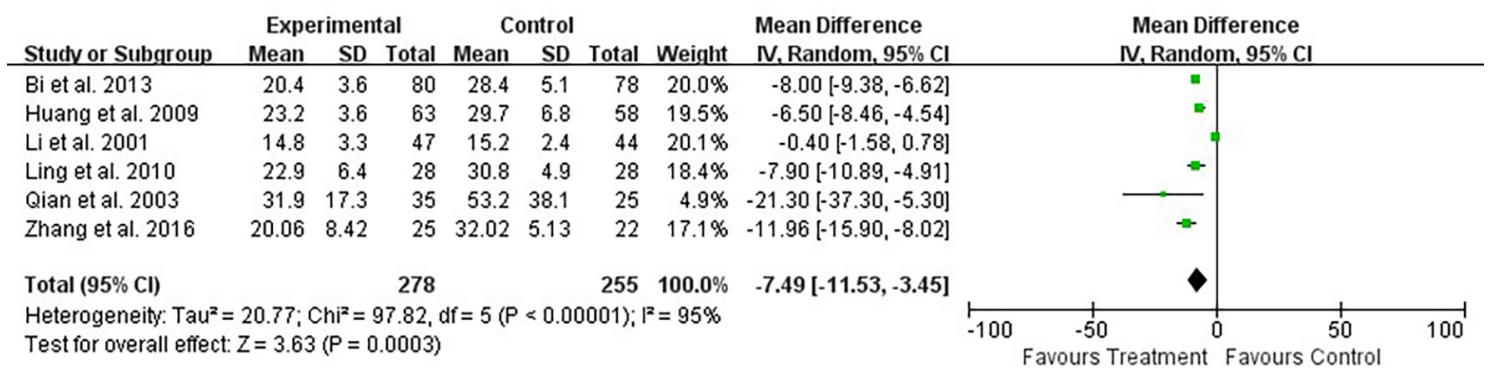

Figure 13 Forest plot of 5-day post operation TBIL. TBIL, total bilirubin.

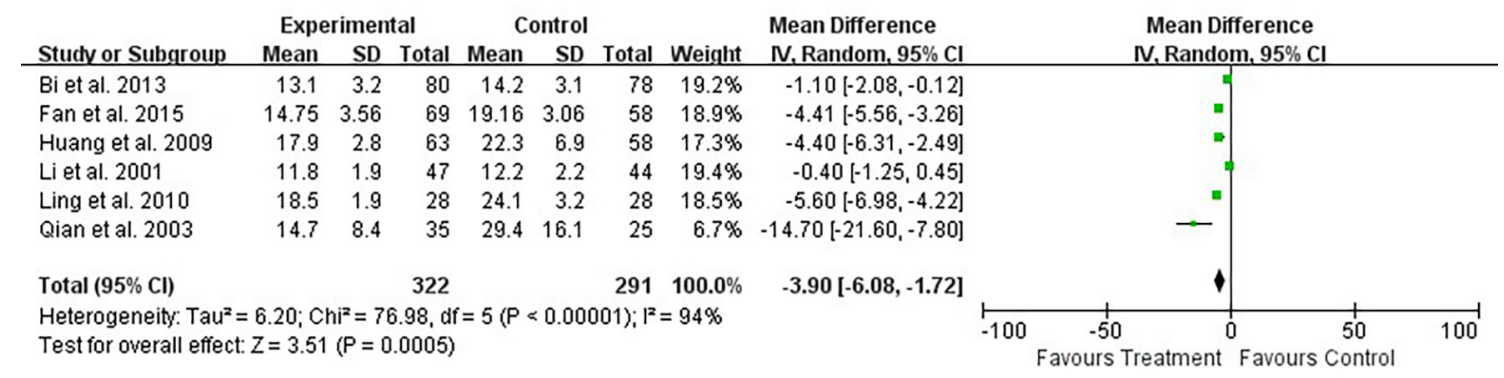

Figure 14 Forest plot of 7-day post operation TBIL. TBIL, total bilirubin. 
one of the included RCTs was at low risk of bias, reflecting poor study design of lacking adequate randomization and blinding in the field of hepatectomy. Poor study design can lead to erroneous conclusions (38). The end points of the nine RCTs included in this meta-analysis are not exactly the same, increasing the possibility of selection bias. The number of studies included was few. Thus, there is a high risk of type I and type II errors. Therefore, the risk of both random and systematic errors in the trials assessed in this review is high.

Since surgical skills, operators' experience and the application of new devices all affect patients' outcomes significantly, inclusion of earlier studies may partly explain the high heterogeneity of the results. Due to apparent heterogeneity across studies and a paucity of included studies, the findings from our study should be dealt with some caution.

Adequately powered and better-designed RCTs are required, including the identification of more appropriate markers of liver function or dysfunction under treatment of UTI. Along with recent UTI related clinical studies also indicated the anti-inflammatory effect in the IR injury and hence plays a predominant role in organ protection (39-41). This may aid in the treatment of patients undergoing hepatectomy with vascular occlusion and improve outcome.

\section{Acknowledgments}

Funding: None.

\section{Footnote}

Conflicts of Interest: All authors have completed the ICMJE uniform disclosure form (http://dx.doi.org/10.21037/ apm.2020.04.28). The authors have no conflicts of interest to declare.

Ethical Statement: The authors are accountable for all aspects of the work in ensuring that questions related to the accuracy or integrity of any part of the work are appropriately investigated and resolved.

Open Access Statement: This is an Open Access article distributed in accordance with the Creative Commons Attribution-NonCommercial-NoDerivs 4.0 International License (CC BY-NC-ND 4.0), which permits the noncommercial replication and distribution of the article with the strict proviso that no changes or edits are made and the original work is properly cited (including links to both the formal publication through the relevant DOI and the license). See: https://creativecommons.org/licenses/by-nc-nd/4.0/.

\section{References}

1. Hardy KJ. Liver surgery: the past 2000 years. Aust N Z J Surg 1990;60:811-7.

2. Simillis C, Li T, Vaughan J, et al. Methods to decrease blood loss during liver resection: a network meta-analysis. Cochrane Database Syst Rev 2014;(4):CD010683.

3. Gurusamy KS, Kumar Y, Ramamoorthy R, et al. Vascular occlusion for elective liver resections. Cochrane Database Syst Rev 2009;(1):CD007530.

4. Saidi RF, Kenari SK. Liver ischemia/reperfusion injury: an overview. J Invest Surg 2014;27:366-79.

5. Zhai Y, Petrowsky H, Hong JC, et al. Ischaemiareperfusion injury in liver transplantation--from bench to bedside. Nat Rev Gastroenterol Hepatol 2013;10:79-89.

6. Shulman NR. A proteolytic inhibitor with anticoagulant activity separated from human urine and plasma. J Biol Chem 1955;213:655-71.

7. Li W, Qiu X, Jiang H, et al. Ulinastatin inhibits the inflammation of LPS-induced acute lung injury in mice via regulation of AMPK/NF- $\kappa \mathrm{B}$ pathway. Int Immunopharmacol 2015;29:560-7.

8. Song D, Song G, Niu Y, et al. Ulinastatin activates haem oxygenase 1 antioxidant pathway and attenuates allergic inflammation. Br J Pharmacol 2014;171:4399-412.

9. Sung YH, Shin MS, Ko IG, et al. Ulinastatin suppresses lipopolysaccharide-induced prostaglandin E2 synthesis and nitric oxide production through the downregulation of nuclear factor- $\mathrm{\kappa B}$ in BV2 mouse microglial cells. Int J Mol Med 2013;31:1030-6.

10. Nobuoka T, Mizuguchi T, Oshima H, et al. Impaired liver regeneration with humoral and genetic disturbances in urinary trypsin inhibitor-deficient mice. Liver Int 2009;29:979-87.

11. Ambiru S, Miyazaki M, Sasada K, et al. Effects of perioperative protease inhibitor on inflammatory cytokines and acute-phase proteins in patients with hepatic resection. Dig Surg 2000;17:337-43.

12. Shu $\mathrm{H}, \mathrm{Liu} \mathrm{K}, \mathrm{He} \mathrm{Q}$, et al. Ulinastatin, a protease inhibitor, may inhibit allogeneic blood transfusionassociated pro-inflammatory cytokines and systemic inflammatory response syndrome and improve postoperative recovery. Blood Transfus 2014;12 Suppl 1:s109-18. 
13. Liberati A, Altman DG, Tetzlaff J, et al. The PRISMA statement for reporting systematic reviews and metaanalyses of studies that evaluate health care interventions: explanation and elaboration. Ann Intern Med 2009; 151:W65-94.

14. Higgins JPT, Green S. editors. Cochrane Handbook for Systematic Reviews of Interventions Version 5.1.0. London: The Cochrane Collaboration, 2011. Available online: http://www.cochrane-handbook.org

15. Gurusamy KS, Gluud C, Nikolova D, et al. Assessment of risk of bias in randomized clinical trials in surgery. Br J Surg 2009;96:342-9.

16. Higgins JP, Thompson SG. Quantifying heterogeneity in a metaanalysis. Stat Med 2002;21:1539-58.

17. DerSimonian R, Laird N. Meta-analysis in clinical trials. Control Clin Trials 1986;7:177-88.

18. Zhang $\mathrm{P}$, Zhang WZ. Protective effects of ulinastatin on the liver function after partial hepatectomy. Journal of Hepatobiliary Surgery 2016;24:122-6.

19. Fan H, Zhang SJ. Effect of ulinastatin in patients with hepatectomyby reduced HMGB1 and inflmmatory levels. Journal of Hepatobiliary Surgery 2015;23:255-8.

20. Bi JG, Yu XF, Bao SY, et al. Application of ulinastatin in the perioperative period of hepatectomy. The Journal of Practical Medicine 2013;29:2243-5.

21. Yang H, Mao Y, Lu X, et al. The effects of urinary trypsin inhibitor on liver function and inflammatory factors in patients undergoing hepatectomy: a prospective, randomized, controlled clinical study. Am J Surg 2011;202:151-7.

22. Ling P, Gong KM. Protective effect of ulinastatin on liver function in patients undergoing hepatectomy with portal blood flow occlusion. Shandong Medical Journal 2010;50:71-2.

23. Huang QX, Jia XM, Xu Z, et al. High mobility group Box-1 protein inhibition and liver function protection of ulinastatin in patients underwent hepatectomy. Journal of Medical Research 2009;38:57-9.

24. Li LW, Huang H. Effect of ulinastatin on perioperative stage cytokine and liver function in patients undergoing hepatectomy. Practical Preventive Medicine 2005;12:759-60.

25. Qian YB, Xiong QJ, Geng XP. Protect effect of ulinastatin in hepatectomy. Journal of Clinical Surgery 2003;11:176-7.

26. Li LQ, Peng MH, LU BY, et al. Protective effect of ulinastatin on liver and kidney after hepatetomy. Chinese Journal of Hepatobiliary Surgery 2001;7:249-51.
27. Sumi H, Takada Y, Takada A. Studies on human urinary trypsin inhibitor. 1. Its modification on treatment of urine with acid. Thromb Res 1977;11:747-54.

28. Muramatu M, Mori S, Matsuzawa Y, et al. Purification and characterization of urinary trypsin inhibitor, UTI68, from normal human urine, and its cleavage by human uropepsin. J Biochem 1980;88:1317-29.

29. Yokoe M, Takada T, Mayumi T, et al. Japanese guidelines for the management of acute pancreatitis: Japanese Guidelines 2015. J Hepatobiliary Pancreat Sci 2015;22:405-32.

30. World Health Organization. WHO Global strategy for containment of antibiotic resistance. Geneva: World Health Organization, 2001.

31. Okuhama Y, Shiraishi M, Higa T, et al. Protective effects of ulinastatin against ischemia-reperfusion injury. J Surg Res 1999;82:34-42.

32. Kudo Y, Egashira T, Yamanaka Y. Protective effect of ulinastatin against liver injury caused by ischemiareperfusion in rats. Jpn J Pharmacol 1992;60:239-45.

33. Li M, Zhang C, Zhang T, et al. Outcome using selective hemihepatic vascular occlusion and Pringle maneuver for hepatic resection of liver cavernous hemangioma. World J Surg Oncol 2015;13:267.

34. Fu SY, Lau WY, Li GG, et al. A prospective randomized controlled trial to compare Pringle maneuver, hemihepatic vascular inflow occlusion, and main portal vein inflow occlusion in partial hepatectomy. Am J Surg 2011;201:62-9.

35. Pietsch UC, Herrmann ML, Uhlmann D, et al. Blood lactate and pyruvate levels in the perioperative period of liver resection with Pringle maneuver. Clin Hemorheol Microcirc 2010;44:269-81.

36. Abu-Amara M, Gurusamy K, Hori S, et al. Systematic review of randomized controlled trials of pharmacological interventions to reduce ischaemia-reperfusion injury in elective liver resection with vascular occlusion. HPB (Oxford) 2010;12:4-14.

37. Zhao Y, Cai H, Zhou P, et al. Protective effect of ulinastatin on hepatic ischemia reperfusion injury through autophagy activation in Chang liver cells. J Cell Biochem 2019;120:14960-70.

38. Wood L, Egger M, Gluud LL, et al. Empirical evidence of bias in treatment effect estimates in controlled trials with different interventions and outcomes: metaepidemiological study. BMJ 2008;336:601-5.

39. Wang H, Liu B, Tang Y, et al. Improvement of sepsis prognosis by ulinastatin: a systematic review and meta- 
analysis of randomized controlled trials. Front Pharmacol 2019;10:1370.

40. Wang $Y$, Peng C, Zhang Z, et al. Intravenous infusion of ulinastatin attenuates acute kidney injury after cold

Cite this article as: Gao H, Lyu Y, Yang Y, Li Y, Cao H. Perioperation ulinastatin intervention protects liver function in hepatectomy: a systematic review of randomized controlled trials and meta-analysis. Ann Palliat Med 2020;9(3):774-787. doi: 10.21037/apm.2020.04.28 ischemia/reperfusion. Int Urol Nephrol 2019;51:1873-81.

41. Xu Q, Yan Q, Chen S. Use of ulinastatin was associated with reduced mortality in critically ill patients with sepsis. J Thorac Dis 2019;11:1911-8. 